\title{
Conclusiones y resumen general
}

Se discuten y comparan los resultados del estudio en el animal de la toxicidad de diferentes inhibidores de la monoaminoxi-dasa. especialmente $<$ Tersavid $>$. Se exponen los diferentes intentos de relacionar las propiedades bioquímicas y farmacológicas de esta clase de sustancias con sus efectos clínicos sobre el dolor pectangmoso. He aquí algunas de las hipotesis propuestas para explicar el mecanismo de acción:

Aumento de la tasa de 5-hidroxitriptamina en sangre, con disminución de la resistencia coronaria y aumento del flujo coronario (sin incremento del consume de oxígeno del ventrículo izquierdo); aumento de la capacidad de fijación del corazón para las catecolaminas y, consecuentemente, posibilidad de impedir los efectos isquemizantes de estas aminas;

disminución de las necesidades de oxígeno del miocardio (cambios en el metabolismo del miocardio) o mejor aprovechamiento del oxígeno;

bloqueo de la transmisión neurohumoral (disminución de la conducción dolorosa); posible participación de la inhibición de la diamino-oxidasa.

De los 594 casos valorables de angina de pecho tratados con Tersavid, respondieron favorablemente 384 , es decir el $65 \%$ o, aproximadamente, los $3 / 8$. La respuesta favorable consistió en una clara reducción de la frecuencia e intensidad de los ataques. Este efecto positivo se confirmó en una casuística estudiada con arreglo a la técnica del doble test ciego. El tanto por ciento de éxitos hu-biera sido probablemente otro si en algunos de los grupos de en-fermos tratados no hubieran predominado clara e intencionada-mente los casos graves o si no se hubieran utilizado dosis demasia-do bajas a consecuencia de la prudencia que exigía la falta de ex-periencia previa.

En un cierto número de casos con electrocardiograma anor-mal, se observó durante el tratamiento con Tersavid una notable mejoría en los signos de isquemia o dejó de presentarse el aumento de los signos eléctricos anormales que habitualmente aparece en el electrocardiograma de esfuerzo. Estos hallazgos son aceptables,

Conclusiones y resumen general

287

por lo demás, solo con reserva, debido al número todavía relativa-mente pequeño de casos y de lo problemático que resulta la inter-pretación de tales resultados.

Algunos pacientes con infarto reciente de miocardio recibieron también Tersavid sin que se evidenciara ningún efecto per judicial. Los dolores residuales post infarto respondieron a veces bien, a veces solo moderadamente.

El tratamiento con anticoagulantes, frecuentemente indispensable en esle tipo de enfermos, debe y puede ser continuado simul-táneamente a la administración de Tersavid, que es también compatible con el resto de las medidas terapéuticas a utilizar en todo ení'ermo anginoso. El tratamiento con Tersavid parece se debe mantener indefinidamente, aun cuando en un cierto número de casos el efecto de la medicación persistió durante largo tiempo después de su supresión. No parece que dicho efecto anlianginoso vaya perdiéndose a lo largo de un tratamiento prolongado. En una de las casuísticas expuestas se menciona además un efecto 
favorable sobre la claudicación intermitente. La dosis inicial útil de Tersavid parece encontrarse entre los 150 y los $300 \mathrm{mg}$. diarios y la dosis diaria de mantenimiento en torno a los $100 \mathrm{mg}$., con variaciones individuales entre los 50 y 200. La aparición del efecto tiene lugar generalmente en el curso de la primera semana y ocasionalmente algo más tarde.

Tersavid se tolera muy bien. Los efectos secundarios son poco importantes. Merece especial mention la carencia de efectos hípo-tensores. En contados pacientes con infarto reciente del miocardio se observaron manifestaciones de hipotensión que pueden ser atribuídas a la enfermedad misma. Tersavid muestra también un efecto psicoestimulante mínimo, por lo que se aproxima mu-cho al desideratum mencionado en la introducción.

Pruebas funcionales hepáticas y exámenes de sangre y orina no mostraron nada anormal durante el tratamiento con Tersavid. Dos pacientes con cirrosis hepática lo toleraron también perfectamente. Otro enfermo que contrajo una hepatitis en el curso de un brote epidémico familiar, continuó recibiendo Tersavid sin que se alterara la evolución favorable de la hepatitis. Determinaciones en sangre de ácido láctico, ácido pirúvico, ácido adenosintrifos-fórico, lactácido-dehidrogenasa, SGO-1 y SGP-2transaminasas apor-

1 Sero-glutamin-oxalacética.

2 Sero-glutamin-piruvica.

288

Conclusiones y resumen general

taron algunos argumentos hiteresantes en apoyo de una de las hipótesis expuestas por los

farmacólogos. Sin embargo, no es posible todavía establecer conclusiones, dado lo reducido y lo provisional de los hallazgos.

Si se comparan dosis iguales, Tersavid es menos activo que el prototipo $<$ Marsilid $>$. El primero tiene, sin embargo, un índice tera-péutico mucho más amplio, gracias a su notable inocuidad, y puede ser dosificado más liberalmente. Puesto que la respuesta a este tipo de terapéutica varía mucho individualmente, es una gran ventaja para el Tersavid la posibilidad de ser manejado den-tro de un amplio margen de dosis, facilitándose así el tratamiento ambulatorio. Debido a su buena eficacia (aunque en algunos casos no al-cance la del Marsilid), y gracias a su excelente tolerancia, el Tersavid parece ser el preparado más recomendable para iniciar un tratamiento con inhibidores de la monoaminoxidasa en un caso de angina de pecho. Si un paciente no responde al Tersavid después de haberlo recibido a dosis y durante un plazo suficientes, puede después ser travado con otros preparados del mismo tipo de ac-ción, por ejemplo el prototipo Marsilid. Ello es especialmente aconsejable cuando el paciente está además muy deprimido o pa-dece una hipertensión. En tales casos debe decidir el clínico si utilizar ya de entrada Marsilid (según las recomendaciones expuestas en el Suplemento al volumen 35 de esta misma revista), o hacer primero un tratamiento de prueba con Tersavid. 